\title{
Anesthetic management of a ventilator-dependent parturient with the King-Denborough syndrome
}

\author{
[La prise en charge anesthésique d'une parturiente en ventilation assistée inter- \\ mittente, atteinte du syndrome de King-Denborough]
}

Ashraf S. Habib MB BCH MSc FRCA, Simon Millar MB CHB FRCA, Peter Deballi III mD, Holly A. Muir MD FRCPC

Purpose: The King-Denborough syndrome (KDS) is a rare disorder that is associated with myopathy, susceptibility to malignant hyperthermia $(\mathrm{MH})$ as well as congenital skeletal and facial anomalies. We report the anesthetic management of a parturient with KDS.

Clinical features: We describe the management of a 24-yr-old primiparous woman with a diagnosis of KDS and a history of previous $\mathrm{MH}$ reaction (age two). Her KDS resulted in chronic respiratory failure. She had a permanent tracheostomy and required overnight ventilatory support for the previous two years. She had three admissions during her pregnancy, one for pneumonia and two for preterm labour. Labour was induced at 37 weeks. Her labour was managed in the operating room where a "clean" anesthesia machine was ready. Cooling aids and a $\mathrm{MH}$ emergency kit were immediately available. Intravenous access, an arterial line and a lumbar epidural catheter were inserted before induction of labour.

Ropivacaine $0.08 \%+$ fentanyl $2 \mu \mathrm{g} \cdot \mathrm{mL}^{-1}$ were used for patientcontrolled epidural analgesia. After $6.5 \mathrm{hr}$ of labour the patient required ventilation. An outlet forceps was performed for delivery. Postpartum, she was ventilated overnight in the intensive care unit. Conclusion: The use of epidural analgesia, close monitoring and collaboration between the various disciplines were important in achieving a safe and uneventful labour in this high-risk parturient.

Objectif : Le syndrome de King-Denborough (SKD) est une affection rare, associée à une myopathie, une susceptibilité à l'hyperthermie maligne (HM) et à des anomalies squelettiques et faciales congénitales. Nous présentons la prise en charge anesthésique d'une parturiente atteinte du SKD.

Éléments cliniques : La patiente est une primipare de 24 ans atteinte du SKD et qui a présenté, à l'âge de deux ans, une réaction d'HM. Le SKD a entraîné une insuffisance respiratoire chronique. Porteuse d'une trachéotomie permanente, la patiente avait besoin d'une assistance ventilatoire pendant la nuit depuis deux ans. Elle avait été hospitalisée trois fois déjà pendant sa grossesse, une fois pour une pneumonie et deux fois pour un travail prématuré. Le travail a été induit à 37 semaines. Il a été pris en charge dans la salle d'opération où un appareil d'anesthésie non contaminé était prêt à utiliser. Du matériel de refroidissement et une trousse d'urgence pour l'HM étaient aussi disponibles. Un accès intraveineux a été pratiqué, et un cathéter intra-artériel et un cathéter péridural lombaire insérés avant l'induction du travail. La ropivacaine à 0,08 \% avec du fentanyl (2 $\mu \mathrm{g} \cdot \mathrm{mL}^{-1}$ ) ont servi à l'analgésie épidurale autocontrôlée. Après $6,5 \mathrm{~h}$ de travail, la patiente a eu besoin de ventilation. L'accouchement a été réalisé avec l'application de forceps. En post-partum, la patiente a été sous ventilation pendant la nuit à l'unité des soins intensifs.

Conclusion : L'utilisation d'analgésie épidurale, d'une surveillance étroite et de la collaboration multidisciplinaire ont assuré un travail obstétrical sûr et sans incident chez une parturiente à haut risque.

$\mathrm{T}$ HE King-Denborough syndrome (KDS) is a rare disorder that consists of multiple congenital facial and skeletal deformities along with a slowly progressive myopathy and susceptibility to malignant hyperthermia $(\mathrm{MH})$. We report the anesthetic management of pregnancy with a successful outcome in a 24 -yr-old woman with KDS who had a permanent tracheostomy and was ventilator dependent.

\section{Case report}

A 24-yr-old primiparous Lumbee Indian woman at 20 weeks gestation was referred from a peripheral hospital. She was known to have KDS, diagnosed after a $\mathrm{MH}$ reaction was suspected during cleft palate repair at the age of two. At that time, following inhalational

From the Division of Women's Anesthesia, Department of Anesthesiology, Duke University Medical Center, Durham, North Carolina, USA. Address correspondence to: Dr. Ashraf S. Habib, Division of Women's Anesthesia, Department of Anesthesiology, Duke University

Medical Center, Box 3094, Durham, NC 27710, USA. Phone: 919-681-6535; Fax: 919-668-6265; E-mail: habib001@mc.duke.edu Accepted for publication December 23, 2002.

Revision accepted March 12, 2003. 
induction of anesthesia with halothane, the patient developed severe rigidity, laryngeal and carpopedal spasm, as well as severe tachycardia with a $1^{\circ} \mathrm{C}$ rise in temperature over $30 \mathrm{~min}$. The procedure was abandoned on that occasion. Two weeks later, the operation was performed using a total iv technique (thiopentone and ketamine) and avoiding the use of succinylcholine. A total $i v$ technique was also used for all subsequent anesthetics in this patient.

She also had chronic respiratory failure secondary to myopathy and kyphoscolioisis, requiring overnight ventilatory support (from 22:00 till 08:00) for the previous two years. She had a history of recurrent chest infections, however did not require mechanical ventilation until two years ago. At that time she experienced a severe pneumonia requiring a prolonged period of mechanical ventilation. A tracheostomy was done to facilitate weaning. However, she remained ventilator dependent since this event.

Her past medical history included delayed motor development and childhood seizures. Previous surgeries included cleft palate repair, pharyngoplasty, tympanoplasty with tympanostomy tube insertion, muscle biopsy at the age of five (which showed non-specific myopathy), and tracheostomy under local infiltration with lidocaine. Family history was significant for a confirmed history of $\mathrm{MH}$ in her brother during general anesthesia for repair of a traumatic ophthalmic injury.

At the time of admission, the patient was recovering from a pseudomonas pneumonitis requiring treatment with antibiotics and supplemental oxygen.

On examination she weighed $28.5 \mathrm{~kg}$ and was 152.5 $\mathrm{cm}$ tall. She was of normal intelligence and had the characteristic facial appearance of KDS with ptosis, downslanting palpebral fissures, micrognathia, low set ears and overcrowded teeth. Severe kyphoscoliosis and pectus carinatum were also noted. She appeared malnourished with generalized muscle wasting. A tracheostomy with a size 4 Shiley tube was in place. She was receiving $\mathrm{l} \mathrm{L} \cdot \mathrm{min}^{-1}$ of oxygen through a nasal cannula. Her laboratory investigations including creatine phosphokinase $(\mathrm{CPK})$ were within normal limits except for a low albumin $\left[3 \mathrm{~g} \cdot \mathrm{dL}^{-1}\right.$ (normal range $3.9-5 \mathrm{~g} \cdot \mathrm{dL}^{-1}$ )]. Her arterial blood gases $(\mathrm{ABG})$ on $1 \mathrm{~L}$ of oxygen were as follows: $\mathrm{pH}$ : 7.34, $\mathrm{pO}_{2}: 57 \mathrm{mmHg}, \mathrm{pCO}_{2}: 58$ $\mathrm{mmHg}, \mathrm{HCO}_{3}: 30 \mathrm{mmHg}, \mathrm{SaO}_{2}: 87.4 \%$. She made an uneventful recovery from her pneumonia and remained stable throughout the pregnancy with no increase in ventilatory requirements. She was subsequently admitted twice during pregnancy for premature labour, which settled with rehydration on both occasions.

With each admission, the anesthesia machine in one of the operating rooms (OR) was prepared, the vapor- izers were removed, the soda lime changed and the machine was flushed with high flow oxygen. Following collaboration among obstetricians, anesthesiologists, pulmonologists and pediatricians, the patient was admitted for induction of labour at 37 weeks gestation. The fetus had intra-uterine growth retardation and was at the fifth percentile. Although the patient was of small stature the obstetricians felt confident she could achieve a vaginal birth. There were concerns expressed about the ability of the fetus to tolerate labour. However, due to her compromised respiratory status, it was felt that recovery following a vaginal birth would be much smoother than following a Cesarean section (CS).

A decision was made to manage labour in the OR where a "clean" anesthesia machine and ventilatory equipment were available. A dedicated anesthesia and nursing team was organized to manage the patient throughout labour. A bed in the intensive care unit (ICU) was also booked for postdelivery care. The patient's own ventilator, cooling aids and a $\mathrm{MH}$ emergency kit were immediately available.

Following the establishment of $i v$ access, an arterial line was placed in the right radial artery. Despite her severe kyphoscoliosis a lumbar epidural catheter was inserted easily at L3/4 interspace. Ten millilitres of ropivacaine $0.08 \%+$ fentanyl $2 \mu \mathrm{g} \cdot \mathrm{mL}^{-1}$, given in incremental doses of $5 \mathrm{~mL}$, were used for initiation of epidural analgesia. For maintenance, a patient-controlled epidural analgesia system with the same solution was used with an infusion rate of $5 \mathrm{~mL} \cdot \mathrm{hr}^{-1}$, a bolus dose of $5 \mathrm{~mL}$ and a lockout period of eight minutes. After five hours, we increased the infusion rate to 8 $\mathrm{mL} \cdot \mathrm{hr}^{-1}$. Electrocardiogram, pulse oximetry, respiratory rate, invasive blood pressure and temperature were monitored continuously throughout labour. Baseline $\mathrm{ABG}$ on room air were: $\mathrm{pH}: 7.38, \mathrm{PaCO}_{2}: 42 \mathrm{mmHg}$, $\mathrm{PaO}_{2}: 86 \mathrm{mmHg}, \mathrm{HCO}_{3}: 24.6 \mathrm{mmHg}$. Her oxygen saturation $\left(\mathrm{SaO}_{2}\right)$ was $97 \%$, with a respiratory rate of 24 breaths. $\mathrm{min}^{-1}$. Labour was induced using $i v$ oxytocin. The epidural provided good pain relief. After $6.5 \mathrm{hr}$ of labour, the patient became tired and sleepy and requested to be ventilated. $\mathrm{ABG}$ prior to ventilation were: $\mathrm{pH}$ : 7.33, $\mathrm{PaCO}_{2}: 48.5 \mathrm{mmHg}, \mathrm{PaO}_{2}: 85 \mathrm{mmHg}, \mathrm{HCO}_{3}$ : $24.9 \mathrm{mmHg}$ on $\mathrm{FIO}_{2}$ of 0.4 with a $\mathrm{SaO}_{2}$ of $93.3 \%$. Labour progressed smoothly and four hours later the cervix was fully dilated. An outlet forceps was used to assist delivery as the patient did not have the muscle power to push. Six millilitres of plain lidocaine $2 \%$ were used to top up the epidural for forceps delivery. The patient was very sedated towards the time of delivery.

$\mathrm{ABG}$ at the time of delivery were: $\mathrm{pH}: 7.35$, $\mathrm{PaCO}_{2}: 41 \mathrm{mmHg}, \mathrm{PaO}_{2}: 203 \mathrm{mmHg}, \mathrm{HCO}_{3}: 22$ 
$\mathrm{mmHg}$, with a $\mathrm{SaO}_{2}$ of $97.3 \%$. A male infant weighting $2080 \mathrm{~g}$ was born with Apgar scores of 7 and 8 at one and five minutes. A second-degree tear was repaired and the patient was then transferred to the ICU where she was ventilated overnight. She remained hemodynamically stable with satisfactory $\mathrm{ABG}$ and normal temperature. She was discharged from the ICU the following morning and left the hospital four days later.

\section{Discussion}

We report a successful outcome after Cesarean delivery in a patient with KDS. This syndrome was first reported by King and Denborough in 1972 when the authors documented 18 males with $\mathrm{MH}$, five of whom had congenital progressive myopathy, short stature, cryptorchidism, pectus carinatum, lumbar lordosis and thoracic kyphosis. Three of the five had similar facial features with ptosis, downslanting palpebral fissures, micrognathia, crowded teeth, apparently low set ears, and a short webbed neck. ${ }^{1}$ Since then, more cases were reported including cases in females. Cleft palate or high arched palate was described in some patients. ${ }^{2,3}$ Most patients were of normal intelligence. In 1988, Stewart and colleagues ${ }^{4}$ presented six children, all of whom were Lumbee Indians, who had physical features in common with King syndrome. They all had cleft palate and came from a single ethnic group from the same geographic area (south central region of North Carolina). Our patient also came from this same group of Lumbee Indians and shares identical features with the patients described in this report.

The inheritance of King syndrome is unknown and there is little evidence to conclude that it is a single disorder. There are also no strict diagnostic criteria for this syndrome. It may be actually a phenotype resulting from a heterogeneous collection of congenital myopathies with different microscopic appearances. ${ }^{5}$ Original descriptions of this syndrome suggested that it is not familiar but occurs sporadically. However, McPherson and Taylor reported that three out of eight studied patients had at least one relative with elevated CPK levels. In one family, several relatives also had musculoskeletal anomalies. ${ }^{2}$ Serum CPK in patients with KDS may be elevated ${ }^{2}$ or normal. ${ }^{6,7}$ Most of the reported cases of KDS have been ascertained through an episode of MH. It is therefore prudent to treat all KDS patients as MH susceptible (MHS).

The main issues with our patient included $\mathrm{MH}$ susceptibility, myopathy, poor nutritional status, ventilator dependence and severe kyphoscoliosis. Since she had a permanent tracheostomy, any potential problems with the airway, resulting from her craniofacial abnormalities, were, fortunately, eliminated. Thus concerns about emergent intubation and the use of succinylcholine were avoided.

Although two large series have shown that pregnancy is usually well tolerated in patients with kyphoscoliosis, ${ }^{8,9}$ significant morbidity and mortality have also been reported. ${ }^{10}$ The preexisting limitation in ventilation can be exaggerated by pregnancy to the point of precipitating acute respiratory failure. ${ }^{10}$ Labour can further increase the work of breathing and oxygen consumption and may precipitate cardiorespiratory decompensation. This can be further aggravated in the postpartum period by the autotransfusion caused by uterine involution. An ICU bed had been booked in anticipation of decompensation in her respiratory function, however she only required overnight ventilation and was discharged from the ICU the following morning.

We decided to use the patient's ventilator, as she was comfortable and familiar with its operation. We also felt that, psychologically, this approach would make the patient more relaxed. We chose to have the patient labour in the OR, the anesthetic machine of which was prepared for use in this MHS patient, to avoid any possible mistakes that might occur in case of an obstetric emergency.

An arterial line was inserted to facilitate the need for frequent blood sampling. The baseline CPK was normal and we did not repeat it, as the value of CPK measurement is limited. Small increases can be seen with labour with a maximum increase at about $24 \mathrm{hr}$ postpartum, mainly due to myometrial muscle activity. ${ }^{11}$ We did, however, repeat measurements of ABG.

An epidural was inserted prior to the induction of labour as difficulty was anticipated due to her severe kyphoscoliosis. However, an L3/4 epidural was inserted without difficulty. In addition to providing good analgesia for labour, the epidural had several added benefits in our patient. Having an epidural catheter in place, with the patient nursed in the OR, would certainly reduce the chance of requiring a general anesthetic should an obstetrical emergency arise. Good pain relief would also reduce the increased work of breathing and oxygen consumption during labour in our respiratory compromised patient. There is also the additional benefit of stress reduction, although stress has not been reported to trigger a $\mathrm{MH}$ reaction during labour. ${ }^{12}$ Finally, in this patient it was anticipated that an assisted second stage would be required to achieve vaginal delivery and an epidural would help facilitate this. If the epidural analgesia failed, our plan was to use an $i v$ patient controlled analgesia with fentanyl. If an emergency CS was needed, a total iv tech- 
nique avoiding the use of succinylcholine would have been our plan should the epidural have failed to provide adequate analgesia.

We chose not to use dantrolene prophylaxis. However, vials were readily available to us. This approach has been recommended by a number of authors. ${ }^{13,14}$ Dantrolene crosses the placenta and probably crosses into the breast milk; however there appear to be no significant adverse effects on the fetus or infant. ${ }^{15}$ The potential maternal side effects of dantrolene include muscle weakness, drowsiness, dizziness, nervousness, nausea, vomiting, slurred speech and blurred vision, all of which could add to our patient's already compromised respiratory status. ${ }^{13}$ Dantrolene prophylaxis has also been associated with postpartum uterine atony. ${ }^{16}$ Moreover, no case of $\mathrm{MH}$ that failed to respond to dantrolene has been reported, providing the diagnosis is established early and an adequate dose of $i v$ dantrolene administered. ${ }^{13}$ Since our patient was under continuous monitoring, we felt that dantrolene prophylaxis was not warranted.

Although earlier reports recommended the use of ester local anesthetics for epidural analgesia in the MHS parturient, ${ }^{17,18}$ the safety of amide local anesthetics is now well established. ${ }^{19}$ Vasopressors were traditionally listed as drugs to avoid in MHS patients, however the cautious use of ephedrine to treat hypotension associated with neuraxial blocks, has been described without adverse sequelae. ${ }^{12}$ Oxytocin is considered safe but ergot alkaloids should be avoided. ${ }^{20}$

The key to the successful management of a high risk parturient lies in proper planning and collaboration between the various disciplines. Close antenatal, intrapartum and postpartum monitoring were behind the safe and successful management of this patient with KDS.

\section{References}

1 King JO, Denborough $M A, \operatorname{Zapf} P W$. Inheritance of malignant hyperpyrexia. Lancet 1972; 1: 365-70.

2 McPherson EW, Taylor CA Jr. The King syndrome: malignant hyperthermia, myopathy, and multiple anomalies. Am J Med Genet 1981; 8: 159-65.

3 Graham GE, Silver K, Arlet V, Der Kaloustian VM. King syndrome: further clinical variability and review of the literature. Am J Med Genet 1998; 78: 254-9.

4 Stewart CR, Kabler SG, Gilchrist JM. Congenital myopathy with cleft palate and increased susceptibility to malignant hyperthermia: King syndrome? Pediatr Neurol 1988; 4: 371-4.

5 Chitayat D, Hodgkinson KA, Ginsburg O, Dimmick J, Watters $G V$. King syndrome: a genetically heterogenous phenotype due to congenital myopathies. Am J Med Genet 1992; 43: 954-6.
6 Kaplan AM, Bergeson PS, Gregg SA, Curless RG. Malignant hyperthermia associated with myopathy and normal muscle enzymes. J Pediatr 1977; 91: 431-4.

7 Heiman-Patterson TD, Rosenberg HR, Binning CP, Tahmoush AJ. King-Denborough syndrome: contracture testing and literature review. Pediatr Neurol 1986; 2: 175-7.

8 Manning CW, Prime FJ, Zorab PA. Pregnancy and scoliosis. Lancet 1967; 2: 792-5.

9 Siegler D, Zorab PA. Pregnancy in thoracic scoliosis. $\mathrm{Br}$ J Dis Chest 1981; 75: 367-70.

10 Sawicka EH, Spencer GT, Branthwaite MA. Management of respiratory failure complicating pregnancy in severe kyphoscoliosis: a new use for an old technique? Br J Dis Chest 1986; 80: 191-6.

11 Weissberg N, Shemesh O, Schwartz G, Brisk R, Eylath U, Abrabam AS. The rise of serum creatinine levels during labor. Arch Gynecol Obstet 1991; 249: 33-7.

12 Lucy SJ. Anaesthesia for caesarean delivery of a malignant hyperthermia susceptible parturient. Can J Anaesth 1994; 41: 1220-6.

13 Johnson C. Pregnancy and malignant hyperthermia (Letter). J Clin Anesth 1992; 4: 173.

14 Pollock NA, Langton EE. Management of malignant hyperthermia susceptible parturients. Anaesth Intensive Care 1997; 25: 398-407.

15 Shime J, Gare D, Andrews J, Britt B. Dantrolene in pregnancy: lack of adverse effects on the fetus and newborn infant. Am J Obstet Gynecol 1988; 159: 831-4.

16 Weingarten AE, Korsh JI, Neuman GG, Stern SB. Postpartum uterine atony after intravenous dantrolene. Anesth Analg 1987; 66: 269-70.

17 Douglas MJ, McMorland GH. The anaesthetic management of the malignant hyperthermia susceptible parturient. Can Anaesth Soc J 1986; 33: 371-8.

18 Khalil SN, Williams JP, Bourke DL. Management of a malignant hyperthermia susceptible patient in labor with 2-chloroprocaine epidural anesthesia. Anesth Analg 1983; 62: 119-21.

19 MHAUS Professional Advisory Council adopts new policy statement on local anaesthetics. Communicator 1985; 3: 1 .

20 Willatts SM. Malignant hyperthermia susceptibility. Management during pregnancy and labour. Anaesthesia 1979; 34: 41-6. 